\title{
Влияние различных механизмов нагрева слоистого алюмосиликата на сорбционные процессы. Сообщение 1. Сорбция воды при тепловом и электромагнитном (СВЧ) нагреве монтмориллонита
}

\author{
Бельчинская Л.И., Ходосова Н.А., Новикова Л.А. \\ ФГБОУ ВО «Воронежский государственный лесотехнический университет им. Г.Ф. Морозова», \\ Воронеж
}

Поступила в редакцию 18.09.2017 г.

\begin{abstract}
Используется различный механизм нагрева монтмориллонита для повышения его адсорбционной способности: быстрый объёмный нагрев образца электромагнитным излучением СВЧ дециметрового диапазона с частотой 2,45 ГГц и традиционный поверхностный нагрев. Проведены дериватографические исследования, исследована кинетика сорбции воды, определена лимитирующая стадия процесса адсорбции молекул воды. Установлено значительное возрастание сорбционной ёмкости образца, предварительно обработанного в электромагнитном поле СВЧ, как результат его более глубокой дегидратации, и, как следствие, вероятного усиления кислотности его поверхности.
\end{abstract}

Ключевые слова: монтмориллонит, тепловой и электромагнитный СВЧ нагрев, дериватография, адсорбция паров воды, кинетика адсорбции, лимитирующая стадия адсорбции.

\section{Effect of different mechanisms of heating of layered aluminosilicate on sorption processes Communication 1. Effect of preliminary thermal and electromagnetic (microwave) heating of montmorillonite on sorption of water}

\author{
Belchinskaya L.I., Khodosova N.A., Novikova L.A. \\ FSBEI HE «Voronezh State University of Forestry and Technologies named after G.F. Morozov», \\ Voronezh, Russian Federation
}

Clay minerals of layered structure can be applied for production of highly effective sorbents due to variation of their liophilic, structural-sorption and structural-mechanic properties in modification or activation processes (acidic or basic activation, ion-exchange, hydrothermal or ultrasonic treatment, hydrophobization, etc.). Thermal treatment, directed from the surface to interior of the sample, is a conventional way of sorbents activation and regeneration. The present work considered two different mechanisms of heating (thermal heating and heating due transformation of electromagnetic waves of ultrahigh frequency into thermal energy of material) of the sorbent based on natural layered mineral montmorillonite with the purpose of activation of its sorption ability.

Samples of natural aluminosilicate (M95) containing 95\% of montmorillonite and 5\% of illite (deposit in Khakassiya, Russia) were preliminary thermally treated at earlier determined temperature $453 \mathrm{~K}$ for 1 hour to acquire maximal adsorption capacity towards water vapours.

Electromagnetic treatment was carried out at $800 \mathrm{~W}$ power of electromagnetic field for 4 min in a microwave. Thermal analysis was used to determine thermal effects, range of thermal stability and mass loss by thermal treatment of the sorbent. Equilibrium and kinetic dependences of water vapours adsorption by the 
investigated samples of natural and activated sorbent were obtained applying gravimetric method at an equilibrium atmospheric pressure and temperature of $293 \mathrm{~K}$.

Thermal activation of M95 sample increased its sorption capacity to water vapours in 3.3 times, whereas microwave treatment in 5.5 times, mainly, due to aluminosilicate dehydration and release of micropores.

According to derivatograms of natural sample M95 the endoeffect in the range 353-533K was caused by removal of physically bound water from the channels and pores of the sorbent. The loss of mass was $13.5 \%$. Themal treamtnet of the sample led to disappearance of this edoeffect (mass loss of 5.1\%), whereas subsequent adsorption of water vapours again demonstrates this endoeffect as a result of sorbent rehydration.

Applying the two binomial equation of theory of micropore volume filling (TMVF) derived for microporous sorbents, the adsorption of water by investigated M95 sample was calculated.

Kinetic dependences of water vapour adsorption on natural montmorillonite illustrated that adsorption equilibrium was set within 20 hours. The calculated values of internal and external diffusion was correspondingly $1.25 \cdot 10^{-11}$ and $112.0 \cdot 10^{-11} \mathrm{~cm}^{2} / \mathrm{c}$ that determine a stage of internal diffusion of water as limiting stage of adsorption.

Thus, UHF-heating of natural montmorillonite allowed increasing its adsorption capacity to water vapours in more than 5 time and reduce the time of treatment in 15 times comparing to conventional heating.

Keywords: montmorillonite, thermal heating, microwave-heating, derivatography, water adsorption, kinetics of adsorption, limiting stage of adsorption.

\section{Введение}

Согласно второму закону термодинамики, межфазная поверхность стремится к самопроизвольному уменьшению свободной энергии, что является причиной возникновения таких физико-химических явлений, как адсорбция. Эффективность процесса адсорбции во многом определяется выбором сорбента. Основные требования, предъявляемые к адсорбентам: селективность, большая поглотительная способность, невысокая стоимость и доступность. Этим требованиям соответствует природный глинистый минерал монтмориллонит, относящийся к группе слоистых алюмосиликатов, способный к адсорбции и ионному обмену $[1,2]$. Структуру монтмориллонита составляют наноразмерные слои кремнекислородных тетраэдров и алюмокислородных октаэдров, формирующие пластинчатые кристаллы толщиной около 1 нм [3]. Монтмориллонит относится к нанопористым сорбентам с увеличивающимся в процессе адсорбции размером пор на 3-12 нм [4]. Зазоры между контактирующими частицами образуют вторичные, переходные поры с радиусом 5-9 нм. Поверхность и объем вторичных пор значительно ниже первичных. Толщина трехслойного пакета монтмориллонита составляет 9.4 нм [5-6]. В структуре монтмориллонита находится адсорбционная вода и гидроксильная вода решётки. Молекулы воды образуют в составе ионно-гидратного комплекса монтмориллонита [7] три основных типа связи. Первый - гидроксильная связь, образуемая по донорно-акцепторному механизму между атомом водорода молекулы воды и кислородом тетраэдрической сетки. Второй тип - координационная связь между молекулами воды и внеслоевыми катионами. Третий тип - водородные связи между молекулами воды ионно-гидратного слоя в нормальном направлении и в плоскости базальных поверхностей частиц монтмориллонита.

Поверхность природного алюмосиликатного адсорбента энергетически неоднородна. Поэтому одним из основных факторов, влияющих на результативность сорбционных процессов, является наличие и количество активных адсорбционных центров [8]. К активным сорбционным центрам монтмориллонита авторы [9-10] относят обменные катионы (1.05 мг-экв/г), группы $\equiv \mathrm{SiOH}(0.16$ мкмоль/г), группы $=\mathrm{AlOH},-\mathrm{MgOH}\left(0.09\right.$ мкмоль/г), координационно-ненасыщенные ионы $\mathrm{Al}^{3+}, \mathrm{Mg}^{2+}$ (0.04 мкмоль/г); содержание гидроксильных групп для минерала - 0.68 моль/г. Ем- 
кость катионного обмена $\mathrm{Ca}^{2+}, \mathrm{Mg}^{2+}$ равна 0.49 мг-экв/г. В адсорбции полярных веществ кроме поверхностных и межслоевых обменных катионов могут участвовать и другие активные адсорбционные центры - поверхностные гидроксильные группы, поверхностные кислородные атомы, а также молекулы воды, остающиеся на поверхности монтмориллонита после дегидратации [11]. Монтмориллонит обладает значительной емкостью к полярным веществам, в большей степени органическим. Величина адсорбционной ёмкости глинистого минерала по хемосорбционному и молекулярному механизму может достигать удвоенного значения катионообменной емкости.

В качестве адсорбата исследована вода, так как ей отводится основная роль при обсуждении активации глинистого алюмосиликата в процессе гидратации и дегидроксилирования.

Академиком Ф.Д. Овчаренко показано [12], что адсорбционная активность сорбентов в значительной степени зависит от кислотной активации, гидротермальной и ультразвуковой обработок в результате изменений лиофильных, структурносорбционных и структурно-механических свойств, им изучен механизм модифицирования и разработаны оптимальные условия получения высокоэффективных сорбентов на основе глинистых минералов. В ряде работ [13-16] приводятся результаты влияния предварительной термообработки на сорбционную ёмкость природных алюмосиликатов. Как правило, кроме теплового, другие варианты нагрева не рассматриваются. Однако механизм нагрева образца сорбента может быть различен, что должно отражаться на эффективности процессов адсорбции. В данной работе рассматриваются и сравниваются два механизма: тепловой нагрев и нагрев в результате преобразования энергии электромагнитного излучения в тепловую энергию материала.

Теплота, в соответствии с представлениями об атомно-молекулярном строении вещества, рассматривается как беспорядочное непрерывное движение атомов и молекул. При воздействии электромагнитного поля СВЧ резко усиливаются колебания молекул, что приводит к повышению энергии молекул, а, следовательно, возрастанию температуры материала. Нагрев в печи СВЧ основан на принципе дипольного сдвига. Молекулярный дипольный сдвиг под действием электрического поля происходит в образцах, содержащих полярные молекулы. Энергия электромагнитных колебаний поля приводит к постоянному сдвигу молекул, выстраиванию их вдоль силовых линий поля, и образованию дипольного момента. Таким образом, дипольный сдвиг является механизмом преобразования энергии электромагнитного излучения в тепловую энергию материала. Нагрев в микроволновой печи в результате дипольного сдвига под действием переменного электрического поля зависит от характеристик молекул и межмолекулярного взаимодействия в среде. Микроволновый электроприбор использует явление разогрева водосодержащих веществ электромагнитным излучением дециметрового диапазона, обычно с частотой 2,45 ГГц, один мегагерц соответствует одному миллиону колебаний в секунду. За один период поле меняет свое направление дважды. То есть поле, в котором находятся молекулы, меняет полярность 4900000000 раз в секунду. Это является причиной движения молекул с огромной частотой под действием микроволнового излучения. Существенным отличием СВЧ-нагрева от традиционного поверхностного является проникновение энергии электромагнитного поля внутрь образца, быстрый нагрев молекул, продолжительность которого измеряется минутами и распространение энергии по всему объему образца.

Таким образом, целью данной работы является изучение и сравнение эффективности адсорбции паров воды на монтмориллоните при традиционном тепловом 
нагреве и нагреве образца в результате преобразования энергии электромагнитного излучения в тепловую энергию материала.

\section{Эксперимент}

Объектом исследования являлся образец природного алюмосиликата (М95), содержащий 95\% монтмориллонита и 5 \% иллита месторождения Хакассии (Россия). Химический, фазовый состав и физико-химические характеристики образца М95 определены ранее $[17,18]$ и представлены в таблице 1.

Таблица 1. Элементный состав образца природного монтмориллонита М95

\begin{tabular}{|c|c|c|c|c|c|c|c|c|c|c|c|c|}
\hline \multirow{2}{*}{ Образец } & \multirow{2}{*}{$\begin{array}{c}\text { Фазовый } \\
\text { состав }\end{array}$} & \multicolumn{11}{|c|}{ Содержание основных элементов, ат. \% } \\
\hline & & $\mathrm{C}$ & $\mathrm{O}$ & $\mathrm{Na}$ & $\mathrm{Mg}$ & $\mathrm{Al}$ & $\mathrm{Si}$ & $\mathrm{K}$ & $\mathrm{Ca}$ & $\mathrm{Fe}$ & $\mathrm{Cu}$ & $\mathrm{Ti}$ \\
\hline M95 & $\begin{array}{c}\text { Монт- } \\
\text { мориллонит } \\
-95 ; \\
\text { иллит }-5 \%\end{array}$ & 8.25 & 49.01 & 0.53 & 1.08 & 7.63 & 22.93 & 1.21 & 0.71 & 5.79 & 1.94 & 0.51 \\
\hline
\end{tabular}

Термическая обработка. Монтмориллонит подвергали предварительной термообработке при установленной ранее температуре 453 К в течение 1 часа $[17,18]$, соответствующей максимальной адсорбционной емкости по парам воды.

СВЧ-нагрев. Электромагнитная обработка проводилась в СВЧ печи при мощности поля 800 Вт и времени обработки 4 минуты, определенный ранее в качестве оптимальных условий для активации сорбента [17]. Образец массой 1 г взвешивали на аналитических весах с точностью до $10^{-4}$ г до и после облучения. Температура минерала при активации в поле СВЧ измерялась с помощью инфракрасного пирометра AR300, обеспечивающего измерение температур в диапазоне 236-473 К с погрешностью \pm 1 К. В ходе измерений температура поверхности алюмосиликата составляла $427 \mathrm{~K}$, что на 26 К меньше, чем при термообработке.

Термический анализ. Представления о тепловых эффектах при термической обработке сорбента, пределы термической устойчивости и потерю массы при прокаливании получали при дериватографических исследованиях на приборе Q -1500 Д системы «Паулик, Паулик и Эрдеи», который регистрировал изменения на кривых DTA, TG, DTG и T. Интервал температур 293-1173 К. Эталонный материал $\mathrm{Al}_{2} \mathrm{O}_{3}$, скорость нагрева 10 град/мин.

Адсорбция паров воды. Адсорбцию паров воды исследуемыми образцами сорбентов проводили при равновесном атмосферном давлении и температуре 293 К эксикаторным методом, определяя гравиметрически количество адсорбированной воды. Для установления кинетических зависимостей адсорбции паров воды бюксы с природным или активированным сорбентом (три повторения) помещали в эксикатор и через $1 ; 2 ; 4 ; 6 ; 12 ; 16 ; 20: 28 ; 42: 64$ и 140 часов регистрировали изменение массы сорбента достигая постоянных значений.

\section{Обсуждение результатов}

Природные алюмосиликаты обладают развитой геометрической поверхностью, которая характеризуется пористостью, обеспечивающей избыток поверхностной энергии и являющейся одной из основных причин возникновения адсорбционных процессов, имеющих отрицательный энтальпийный эффект. В естественных условиях избыток поверхностной энергии алюмосиликатов скомпенсирован адсорби- 
рованными молекулами воды, углекислого газа, различных органических и неорганических веществ из окружающей среды. Активация адсорбционных свойств поверхности происходит при возникновении условий для десорбции поглощенных молекул, например, когда значения энтальпии принимают положительные значения, т.е. при повышении температуры сорбента (термообработка, СВЧ-воздействие).

Значения адсорбции паров воды природным образцом монтмориллонита, активированного термически и в поле СВЧ при установленных ранее оптимальных режимах приведены в таблице 2.

Таблица 2. Адсорбционная емкость природного, термически и СВЧ-активированного монтмориллонита по парам воды

\begin{tabular}{|c|c|c|}
\hline Сорбент & Условия активации & Адсорбция, ммоль/г \\
\hline М95 & Без активации & 0.67 \\
\hline М95-термо & Т=453 К & 2.23 \\
\hline M95-СВ4 & $\mathrm{W}=800 \mathrm{Bт}, 4$ мин. & 3.66 \\
\hline
\end{tabular}

Термическая активация образца М95 повышает его сорбционную емкость к парам воды в 3.3 раза, а СВЧ-обработка в 5.5 раз. Основной процесс, протекающий как при термическом, так и при СВЧ-воздействии на образец глинистого минерала является дегидратацией, которая приводит к освобождению микропор сорбента и возрастанию его поверхностного натяжения. Тем не менее, степень воздействия традиционного и СВЧ-нагрева на поверхностную активность сорбента существенно отличаются.

Согласно дериватограммам (кривые ДТА) природного (рис. 1а) и термически ( $\mathrm{T=453} \mathrm{К)} \mathrm{(рис.} \mathrm{1б)} \mathrm{активированного} \mathrm{монтмориллонита} \mathrm{при} \mathrm{его} \mathrm{нагреве} \mathrm{протекает}$ ряд физико-химических процессов.

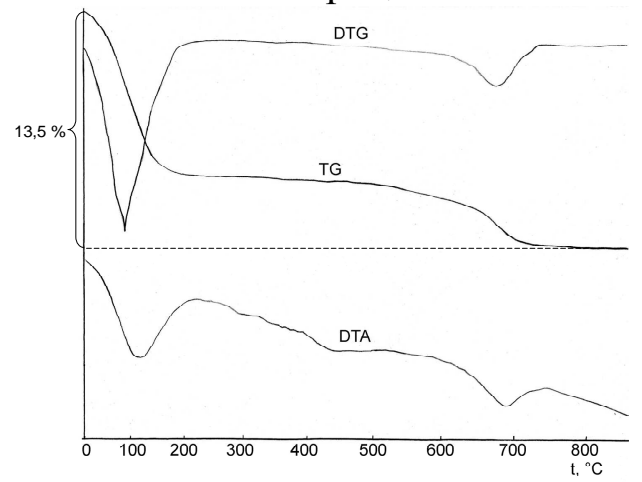

a

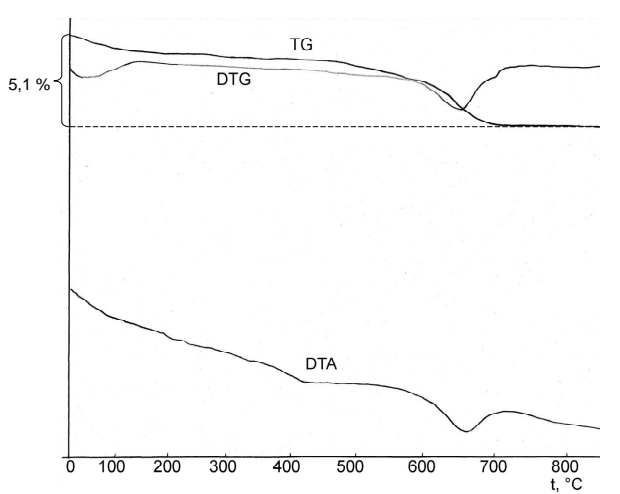

6

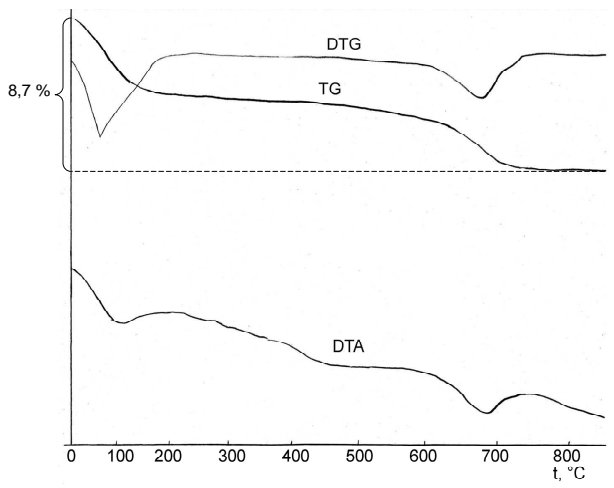

B

Рис. 1. Дериватограммы образца монтмориллонита: а) природный (М95); б) термоактивированный при 453 К (М95-термо); в) термоактивированный при 453 К с последующей адсорбцией $\mathrm{H}_{2} \mathrm{O}$ 
Образец природного минерала М95 имеет эндоэффект в области температур 353-533 К, который связан с деструкцией межмолекулярных связей в системе сорбент - вода и удалением физически связанной воды из каналов и пор сорбента. Термическая обработка приводит к практически полному исчезновению данного эндоэффекта, так как неконституционно связанная вода в большей степени удаляется из образца при предварительной термообработке. Следующая за термообработкой адсорбция паров воды вновь приводит к возникновению слабого эндоэффекта в результате процесса гидратации, но пик на дериватограммах менее выражен.

Потеря массы на природном образце М95 достигает $13.5 \%$ от общей массы образца (табл. 3), в то время как в результате предварительной термооработки эта величина равна $5.1 \%$.

Таблица 3. Область эндоэффектов и потеря массы при дериватографических исследованиях монтмориллонита

\begin{tabular}{|c|c|c|c|c|c|c|c|c|c|}
\hline \multirow[t]{2}{*}{ Сорбент } & \multirow[t]{2}{*}{$\begin{array}{l}\mathrm{m}, \\
\mathrm{M \Gamma}\end{array}$} & \multicolumn{4}{|c|}{$\begin{array}{c}\text { Температурная область эндоэффектов, } \\
\text { К }\end{array}$} & \multicolumn{4}{|c|}{ Потеря массы, мг } \\
\hline & & $\begin{array}{l}\text { I эндоэф- } \\
\text { фект }\end{array}$ & $\min$ & $\begin{array}{l}\text { II эндоэф- } \\
\text { фект }\end{array}$ & $\min$ & I & $\begin{array}{c}\% \text { к ис- } \\
\text { ходной } \\
\mathrm{m}\end{array}$ & II & $\begin{array}{l}\% \text { к ис- } \\
\text { ходной } \mathrm{m}\end{array}$ \\
\hline M95 & 548 & $353-528$ & 433 & $923-1053$ & 1003 & 50 & 9.1 & 74 & 13.5 \\
\hline M95-термо & 549 & - & - & $903-1053$ & 1003 & - & - & 28 & 5.1 \\
\hline $\begin{array}{c}\text { M95- } \\
\text { терм0++ }{ }_{2} \mathrm{O}\end{array}$ & 550 & $373-483$ & 453 & $903-1053$ & 1003 & 22 & 4 & 48 & 8.7 \\
\hline
\end{tabular}

Адсорбция воды на образце М95 приводит к регидроксилированию монтмориллонита и большей потере массы (8.7\%). Эти данные согласуются с результатами, полученными в работе [19], где было обнаружено, что первый эндотермический эффект $\left(120-180^{\circ} \mathrm{C}\right)$ соответствует выделению адсорбированной воды из монтмориллонита, при этом адсорбированная вода полностью выделяется в пределах температур от 50 до $200^{\circ} \mathrm{C}$. Второй эндотермический эффект $\left(560-680^{\circ} \mathrm{C}\right) \quad$ соответствует выделению гидроксильной воды решетки монтмориллонита. Количество гидроксильной воды меньше количества непрочно связанной адсорбированной воды, что отмечается на кривой эндотермическим пиком меньшей величины. Третий эндотермический эффект $\left(800-890^{\circ} \mathrm{C}\right)$ соответствует разрушению кристаллической структуры монтмориллонита, т.е. перевод вещества в аморфное состояние.

Механизм активации сорбента в электромагнитном поле СВЧ отличается от традиционного теплового нагрева. При обработке монтмориллонита в электромагнитном поле СВЧ энергия волны по закону Бугера поглощается в большей степени молекулами воды, образующими межмолекулярные связи с матрицей структуры. Под воздействием поля СВЧ диполи воды непрерывно вращаются перпендикулярно направлению движения электромагнитной волны. При этом мгновенно разрываются межмолекулярные связи между диполями воды и структурной матрицей образца М95. При частоте 2.45 ГГц вращение диполей молекул под действием электрической составляющей электромагнитного поля происходит со скоростью 4.5 миллиарда раз в секунду, что приводит к быстрому разогреву образца во всём объёме, десорбции молекул воды как с поверхности, так и из объёма образца М95. В результате этого адсорбционно активные центры, ранее занятые водой, освобождаются, образец активируется, что отражается на его поглотительной способности. СВЧ-обработка широко используется для осушения и модификации цеолитов, а в последнее время и для 
их регенерации [20-23].

Адсорбционные процессы на микропористых сорбентах успешно описываются теорией объемного заполнения микропор (ТОЗМ) ДубининаРадушкевича [24]. Расчёт адсорбции паров воды на микропористом образце природного цеолита клиноптилолита (область заполнения от 0 до 6 ммоль/г) позволил вывести двухчленное уравнение ТО3М $a=4.2 / \exp (A / 8.0)^{2}+2.0 / \exp (A / 2.7)^{2}[24]$, которое в данной работе использовано для расчёта «а» по воде на глинистом минерале М95 (табл. 4).

Таблица 4. Величина сорбции воды на образце М95, полученная экспериментально и из уравнения ТОЗМ (при Т=453 К)

\begin{tabular}{|l|c|c|}
\hline \multirow{2}{*}{ Сорбент } & \multicolumn{2}{|c|}{ Адсорбция, ммоль/г } \\
\cline { 2 - 3 } & экспериментальные данные & данные, рассчитанные из уравнения ТОЗМ \\
\hline M95 & $2.23 \pm 0.7$ & $2.11 \pm 0.9$ \\
\hline
\end{tabular}

Отличие величины сорбционной ёмкости, полученное экспериментально и рассчитанное по ТОЗМ, составляет 5\%, что подтверждает микропористую структуру глинистого минерала М95 и показывает возможность расширения диапазона использования данного уравнения.

На рис. 2 представлены кинетическая зависимость адсорбции паров воды на природном монтмориллоните, из которой следует, что равновесие адсорбции паров воды на образце М95 устанавливается в течение 20 ч.

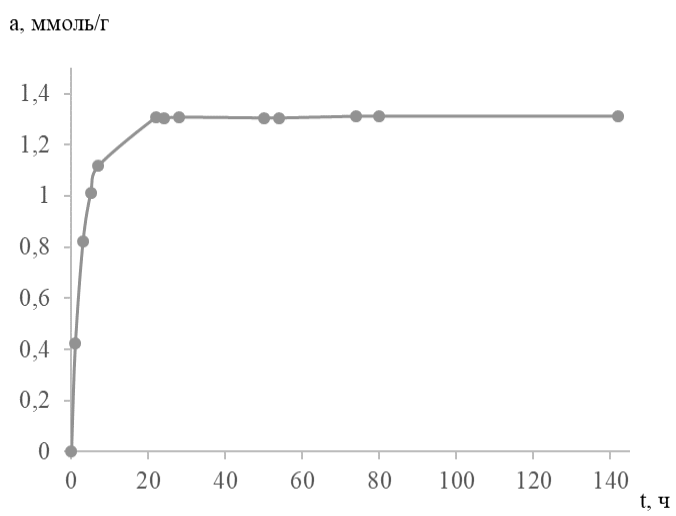

Рис. 2. Кинетическая зависимость адсорбции паров воды на природном образце М95

Для установления лимитирующей стадии процесса сорбции паров воды оценивали величины коэффициентов диффузии. Коэффициент внутренней диффузии рассчитывали по эмпирическому уравнению Знаменского [25]:

$$
\beta \mathrm{t}=-2 \mathrm{~F} \cdot \lg (1-\mathrm{F})
$$

где $\beta=\mathrm{D}_{\text {in }} \cdot \pi^{2} / \mathrm{r}^{2}$ - параметр Бойда, $\mathrm{F}$ - степень заполнения емкости сорбента, D - коэффициент внутренней диффузии, $\mathrm{t}$ - время достижения степени заполнения емкости сорбента, $\mathrm{r}$ - радиус зерна.

Значения коэффициента внешней диффузии молекул воды рассчитывали по формуле [26]

$$
D_{e x}=\frac{0,23 \cdot r_{o} \cdot \delta \cdot k_{p}}{\tau_{1 / 2}},
$$

где $\mathrm{r}_{\mathrm{o}}$ - радиус частицы, $\delta$ - толщина пленки, покрывающей частицу сорбента, состоящая из ассоциатов воды, (10 мкм), кр - коэффициент распределения сорбируемо- 
го вещества, $\tau_{1 / 2}-$ время полуобмена.

Рассчитанная величина коэффициента внутренней диффузии (табл. 5) на два порядка меньше значения коэффициента внешней диффузии, что позволяет определить лимитирование процесса сорбции воды на образце М95 стадией внутренней диффузии.

Таблица 5. Коэффициенты внешней и внутренней диффузии при адсорбции молекул воды на М95

\begin{tabular}{|c|c|c|}
\hline Образец & $\mathrm{D}_{\mathrm{ex}} \cdot 10^{11}, \mathrm{~cm}^{2} / \mathrm{c}$ & $\mathrm{D}_{\mathrm{in}} \cdot 10^{11}, \mathrm{~cm}^{2} / \mathrm{c}$ \\
\hline M95 & $112 \pm 0.8$ & $1.25 \pm 0.9$ \\
\hline
\end{tabular}

Установлено, что изменение механизма нагрева алюмосиликатов отражается на соотношении кислых и основных активных центров, которые, как известно, играют большую роль в адсорбционных процессах $[27,28]$. Поверхностная кислотность глинистых минералов характеризует их способностью отдавать протон или электронную пару для образования поверхностных связей. Обычно подобные эффекты достигаются за счет различных групп, присутствующих на поверхности: обменные катионы (для монтмориллонита это $\left.\mathrm{K}^{+}, \mathrm{Na}^{+}, \mathrm{Ca}^{2+}[29]\right)$, координационно ненасыщенные ионы $\mathrm{Al}^{3+}, \mathrm{Mg}^{2+}, \mathrm{Fe}^{3+}$, гидроксильные группы и анионы кислорода [30].

В [31] с использованием метода тестовой каталитической реакции конверсии метилбутинола определено возрастание вклада кислотных центров при предварительной обработке образца цеолита в СВЧ-электромагнитном поле по сравнению с природным и термически активированным катализатором. Выход продуктов, образующихся при участии кислотных центров цеолита вырос на $20 \%$ после обработки катализатора в ЭМП СВЧ. В случае СВЧ-обработки глинистого минерала монтмориллонита, вслед за дегидратацией следует ожидать возрастания кислотности его поверхности, аналогично поведению цеолита, очевидно, за счет усиления поляризации молекул воды в гидратных оболочках обменных катионов.

\section{Заключение}

Установлено влияние механизма предварительного нагрева природного глинистого минерала монтмориллонита на сорбционную ёмкость по парам воды. Определено, что при поверхностном тепловом нагреве образца природного монтмориллонита в течение одного часа поглощение воды возрастает более, чем в три раза. Найдены преимущества электромагнитной обработки (СВЧ-нагрев) монтмориллонита, позволяющей повысить адсорбционную емкость по парам воды более чем в 5 раз сравнительно с природным образцом и около двух раз при поверхностном нагреве, и установить сокращение времени обработки в 15 раз.

Дериватографический анализ позволил определить область эндоэффектов и потерю массы образца при использовании двух механизмов предварительного нагрева и показать преимущество электромагнитного (СВЧ). На основании кинетических исследований определена лимитирующая стадия внутренней диффузии при сорбции молекул воды на глинистом минерале монтмориллоните.

\section{Список литературы}

1. Глины, их минералогия, свойства и практическое значение / под ред. Ф.В. Чухрова. М. Наука. 1970. 272 с.
2. AlSawalha M., Obra E., Roessner F. // Сорбиионные и хроматографические проиессы. 2016. Т. 16. № 6. С. 781-787. 
3. Бетехтин А.Г. Курс минералогии. М. Гос. Научно-технич.изд.литер. по геологии и охране недр. $1951.558 \mathrm{c}$.

4. Юрченко В.В., Свиридов А.В., Свиридов В.В., Никифоров А.Ф. и др. // Сорбционные и хроматографические прочессы. 2017. T. 17. № 3. С. 506-5012.

5. Смолеговский А.М. Развитие представлений о структуре силикатов. М. Наука. 1979. $231 \mathrm{c}$.

6. Куковский Е.Г. Особенности кристаллохимии слоистых алюмосиликатов по данным радиоспектроскопии. Киев. Наукова думка. 1973. $126 \mathrm{c}$.

7. Федоринин Р.П., Храмченков Р.П. // Ученые записки Казанского государственного университета. 2010. Т. 152. кн.1, Естественные науки. С.270-274.

8. Novikova L.A., Strelnikova O.Yu., Khodosova N.A., Belchinskaya L.I. et al. // Сорбиионные и хроматографические проиессы. 2014. T. 14. № 2. C. 185-189.

9. Vasiliev H.G., Ovcharenko F.D. // Proc. Intern. Conference of Colloid and Surface Science. - Budapest: Academiai Klado.1975. pp. 19-26.

10.Бельчинская Л.И., Ходосова Н.А., Стрельникова О.Ю., Петухова Г.А. и др. // Физикохимия поверхности и защита материалов. 2015. Т. 51. № 5. С. 1-8.

11.Barrer R.M. Zeolites and clay minerals as sorbents and molecular sieves. London - New York - San Francisco: Acad. Press. 1978. 498 p.

12.Овчаренко Ф.Д. Гидрофильность глин и глинистых минералов. Киев. Изд-во АН УССР. 1961. $275 \mathrm{c}$.

13. Тарасевич Ю.И., Овчаренко Ф.Д. Адсорбция на глинистых минералах. Киев. Наукова думка. 1975. 352 с.

14. Тарасевич Ю.И. Строение и химия поверхности слоистых силикатов. Киев. Наукова думка. 1988. 248 с.

15. Цицишвили Г.В. Природные минеральные сорбенты. Киев. Изд-во Ан УССР. 1960. C. 63.

16.Kotova D.L., Artamonova M.N., Krysanova T.A., Novikova L.A. et al. // Сорбционные и хроматографические прочессы. 2016. Т 16. № 3. pp. 390-395.

\section{References}

1. Gliny, ikh mineralogiya, svoistva I prakticheskoe primenenie, pod red. F.V. Chekhrova,
17. Belchinskaya L.I., Khodosova N.A., Bityutskay L.A. // Protection of Metals and Physical Chemistry of Surfaces. 2009. Vol. 45. No 2. pp. 203-206

18. Ходосова Н.А. Дисс... канд. хим. наук. Иваново, 2009. 184 с.

19. Сендеров, Э.Э. Цеолиты, их синтез и условия образования в природе М. Наука. 1970. $283 \mathrm{c} /$

20. Polaert I., Ledoux A., Estel L., Huyghe R. et al. // Récents Progrès en Génie des Procédés. 2007. No 94. pp. 1-8.

21. Pinchukova N.A., Voloshko A.Yu., Baumer V.N., Shishkin O.V. et al. // Chemical Engineering and Processing. 2015. Vol. 95. pp.151-158

22. Kalantarifard A., Gon J.G., Yang G.S. // Terr. Atmos. Ocean. Sci. 2016. Vol. 27. No 6. pp. 865-875.

23. Бахия Т., Хамизов Р.Х., Бавижев М.Д., Конов М.А. // Сорбичонные и хроматографические прочессы. 2016. Т. 16. № 6. С. 803812.

24. Цицишвили Г.В. Природные цеолиты. М. Химия. 1985. $224 \mathrm{c.}$

25. Знаменский Ю.П. // Журн. Физич.химии. 1993. T. 67. № 7. С. 1924-1927.

26. Родионов А.И., Клушин В.Н., Торочешников Н.С. Техника защиты окружающей среды. Учебник для вузов. М. Химия. 1989. $512 \mathrm{c}$.

27. Novikova L., Belchinskaya L., Roessner F., Alsawalha M. // ActaGeodynamica et Geomaterialia. 2013. Vol. 10. No 4 (172). Pp. 475484.

28. Belchinskaya L.I., Khodosova N.A., Novikova L.A., StrelnikovaO.Yu. et al. // Physical chemistry of surface and protection of materials. 2016. Vol. 52. No 4. pp. 599-606.

29. Bergaya F., Lagaly G. Handbook of Clay Science. Developments in Clay Science 5. Amsterdam: Elsevier. 2013. 787 p.

30. Schoonheydt R. A. // Handbook of Clay Science. Developments in Clay Science / Bergaya F., Theng B.K.G., Lagaly G. Elsevier Ltd., 2006. pp. 87-113.

31. Анисимов М.В. Дисс... канд. техн. наук. Воронеж. 2012. $251 \mathrm{c}$.
M., Nauka, 1970, 272 p. 
2. AlSawalha M., Obra E., Roessner F., Sorbtsionnye i khromatograficheskie protsessy, 2016, Vol. 16, No 6, pp. 781-787.

3. Betekhtin A.G. Kurs mineralogii, M., Gos. Nauchno-tekhnich. isd. liter. po geologii i okhrane nedr., 1951, $558 \mathrm{p}$.

4. Yurchenko V.V., Sviridov A.V., Sviridov V.V., Nikiforov A.F. et al., Sorbtsionnye $i$ khromatograficheskie protsessy, 2017, Vol. 17, No 3, pp. 506-5012.

5. Smolegovskii A.M., Razvitie predstavlenii o structure silikatov, M., Nauka, 1979, 231 p.

6. Kukovskii E.G., Osobennosti kristallokhimii sloistykh alumosilikatov po dannym radiospektroskopii, Kiev, Naukova dumka, 1973, 126 p.

7. Fedorinin R.P., Khramchenkov R.P., Uchenye zapiski Kazanskogo gosudarstvennogo universiteta, 2010, Vol. 152, kn. 1, Estestvennye nauki, pp.270-274.

8. Novikova L.A., Strelnikova O.Yu., Khodosova N.A., Belchinskaya L.I.. et al., Sorbtsionnye $i$ khromatograficheskie protsessy, 2014, Vol. 14, No 2, pp. 185189.http://www.sorpchrom.vsu.ru/articles/2014 0201.pdf.

9. Vasiliev H.G., Ovcharenko F.D., Proc. Intern. Conference of Colloid and Surface Science, Budapest:,Academiai Klado, 1975, pp. 19-26.

10.Belchinskaya L.I., Khodosova N.A., Strelnikova O.Yu. Petukhova G.A. et al., Physikokhimiya poverkhnosti $i$ zaschita materialov, 2015, Vol. 51, No 5, pp. 1-8.

11.Barrer R.M., Zeolites and clay minerals as sorbents and molecular sieves, London - New York - San Francisco, Acad. Press, 1978, 498 p.

12.Ovcharenko F.D., Gidrofilnost glin I glinistykh mineralov, Kiev, Izd-vo AN USSR, 1961, $275 \mathrm{p}$.

13.Tarasevich Yu.I., Ovcharenko F.D., Adsorbtsiya na glinistykh mineralah, Kiev, Naukova dumka, 1975,352 p.

14.Tarasevich Yu.I., Stroenie I khimiya poverkhnosti sloistykh silikatov, Kiev, Naukova dumka, 1988, $248 \mathrm{p}$.

15.Tsitsizshvili G.V., Prirodnye mineralnye sorbenty, Kiev: Izd-vo AN USSR, 1960, pp. 63.

16.Kotova D.L., Artamonova M.N., Krysanova T.A., Novikova L.A. et al., Sorbtsionnye $i$ khromatograficheskie protsessy, 2016, Vol. 16, No 3, pp. 390-395.

Бельчинская Лариса Ивановна - д.т.н., профессор, заведующая кафедрой химии Воро- http://www.sorpchrom.vsu.ru/articles/20160315 .pdf.

17.Belchinskaya L.I., Khodosova N.A., Bityutskay L.A., Protection of Metals and Physical Chemistry of Surfaces, 2009, Vol. 45, No 2, pp. 203-206

18. Khodosova N.A., Diss...kand.khim.nauk, Ivanovo, 2009, $184 \mathrm{p}$.

19.Senderov E.E., Khitarov N.I., Tseolity, ikh sintez I usloviya obrazovaniya v prirode, M., Nauka, 1970. 283 p.

20.Polaert I., Ledoux A., Estel L., Huyghe R., Thomas M., Récents Progrès en Génie des Procédés, 2007, No 94, pp. 1-8.

21.Pinchukova N.A., Voloshko A.Yu., Baumer V.N., Shishkin O.V. et al., Chemical Engineering and Processing, 2015, Vol. 95, pp. 151158.

22.Kalantarifard A., Gon J.G., Yang G.S., Terr. Atmos. Ocean. Sci., 2016, Vol. 27, No 6, pp. 865-875.

23.Bakhiya T., Khamizov R., Bazhiev M.D., Konov M.A, Sorbtsionnye i khromatograficheskie protsessy,. 2016, Vol. 16., No 6, pp. 803-812.

24.Tsitsishvili G.V., Andronikashvili T.G., Kirov G.N., Filizov L.D., Prirodnye tseolity, M., Khimiya, 1985, 224 p.

25.Znamenskii Yu.P., Zhurn. Physich. Khimii. 1993, Vol. 67, No 7, pp. 1924-1927.

26.Rodionov A.I., Klushin V.N., Torocheshnikov N.S., Technica zaschity okrujauschei sredy. Uchebnik dlya vuzov, M., Khimiya, 1989, $512 \mathrm{p}$.

27.Novikova L., Belchinskaya L., Roessner F., Alsawalha M., ActaGeodynamica et Geomaterialia, 2013, Vol. 10, No 4 (172), pp. 475484. DOI 10.13168/AGG.2013.0048. IF=0.561.

28. Belchinskaya L.I., Khodosova N.A., Novikova L.A., StrelnikovaO.Yu. et al., Physical chemistry of surface and protection of materials, 2016, Vol. 52, No 4, pp. 599-606. doi:10.1134/S2070205116040055.

29.Bergaya F., Lagaly G., Handbook of Clay Science. Developments in Clay Science 5, Amsterdam, Elsevier, 2013, 787 p.

30.Schoonheydt R.A., Handbook of Clay Science. Developments in Clay Science / Bergaya F., Theng B.K.G., Lagaly G., Elsevier Ltd., 2006, pp. 87-113.

31. Anisimov M.V. Diss... kand. tehn. nauk. Voronezh, 2012. 251 p.

Belchinskaya Larisa I. - doctor of science, professor, head of Department of Chemistry Voronezh 
нежского государственного лесотехнического университета им. Г.Ф. Морозова, Воронеж.

Ходосова Наталия Анатольевна - к.Х.н., доцент кафедры химии, Воронежский государственный лесотехнический университет им. Г.Ф. Морозова, Воронеж.

Новикова Людмила Анатольевна - к.х.н., доцент кафедры химии, Воронежский государственный лесотехнический университет им. Г.Ф. Морозова, Воронеж.
State University of Forestry and Technologies named after G.F. Morozov, Voronezh

Khodosova Nataliia A. - PhD, associate professor of Chemistry Department, Voronezh State University of Forestry and Technologies named after G.F. Morozov, E-mail: nhodosova@mail.ru Novikova Liudmila A. - PhD, associate professor of Chemistry Department, Voronezh State University of Forestry and Technologies named after G.F. Morozov, E-mail: yonk@mail.ru 